\title{
Sistem Pakar Deteksi Penyakit Hipertensi Dan Upaya Pencegahannya Menggunakan Metode Naive Bayes Pada RSUD Pandeglang Banten
}

\author{
Robby Rizky ${ }^{1}$, Susilawati $^{2}$, Zaenal Hakim ${ }^{3}$, Lili Sujai ${ }^{4}$ \\ 1,2,3,4 Jurusan Manajemen Informatika Universitas Mathla'ul Anwar Banten Labuan, Cikaliung, Saketi, Pandeglang \\ - Banten 42273 Telp.(0253) 401555 \\ ${ }^{1}$ robby.rizky@unmabanten.ac.id \\ ${ }^{2}$ susilawati@unmabanten.ac.id \\ ${ }^{3}$ hakimzaenal@unmabanten.ac.id \\ ${ }^{4}$ lili sujai@unma banten.ac.id
}

Intisari - RSUD pandeglang merupakan unit pelaksana teknis dinas kesehatan kabupaten/kota yang bertangguang jawab menyelenggarakan pembangunan kesehatan di wilayah kerja.Diagnosis penyakit hipertensi dibuat untuk membantu dan mempermudah para petugas dalam mendiagnosis penyakit hipertensi. Aplikasi sistem pakar ini dirancang menggunakan. .Flow Of System (FOS), Contex Diagram, Data Flow Diagram (DFD). Entity Relationship Diagram (ERD) dan menggunkan tool Sublime Text ( HTML, CSS PHP dan Javascrip) dan untuk databse menggunakan MySQL, hasilnya berupa Menu Home Gejala Diagnosis dan Solusi . Penerapan aplikasi ini dilakukan dengan menginputkan data pasien dan gejala untuk mendapatkan solusi yang mereka inginkan.

Kata kunci : Diagnosis, Naive Bayes, Hipertensi, Sublime Tex dan MySQL

Abstrack - PANDEGLANG Regional General Hospital is a technical implementing place for district / city health offices that is responsible for organizing health development in the work area. Diagnosis of hypertension is made to assist and facilitate officials in diagnosing hypertension. This expert system application is designed using Flow Of System (FOS), Contex Diagram, Data Flow Diagram (DFD). Entity Relationship Diagram (ERD) and using Sublime Text tools (HTML, CSS PHP and Javascrip) and for databse using MySQL, the result is a Home Menu Diagnosis Symptoms and Solutions. The application of this application is done by inputting patient data and symptoms to get the solution they want. Keywords: Diagnosis, Naive Bayes, Hypertension, Sublime Tex and MySQL

\section{PENDAHULUAN}

Tekanan darah tinggi disebut hipertensi di mana tekanan darah terhadap dinding arteri cukup tinggi, pada umumnya kondisi kesehatan yang sering bermasalah pada manusia yaitu penyakit jantung, stroke, obesitas dan diabetes melitus. Hipertensi juga merupakan penyebab kematian nomor 3 setelah stroke dan tuberkulosis, yakni $6,7 \%$ dari populasi kematian pada semua umur. Masalah hipertensi cenderung meningkat, Prevalensi di perkotaan 39,9\% $(37,0 \%$ - 45,8\%) dan di pedesaan 44,1 $(36,2 \%-51,7 \%)$. Hal ini disebabkan karena jantung harus bekerja lebih keras dari biasanya untuk mengedarkan darah melalui pembuluh darah ke seluruh tubuh. Tekanan darah umumnya diukur dengan alat yang disebut Sphygmomanometer yang terdiri dari sebuah pompa, sebuah pengukur tekanan dan sebuah manset dari karet. Alat ini mengukur tekanan darah dalam unit yang disebut milimeter air raksa $(\mathrm{mmHg})$.

RSUD Pandeglang memiliki 2000 lebih pasien yang mengidap penyakit hipertensi, karena banyaknya pasien dan beberapa dokter yang menangani penyakit hipertensi, hal ini menyebabkan kurangnya penanganan langsung pada pasien.

Dalam mendiagnosis suatu penyakit pada bidang kedokteran dibutuhkan alat bantu seperti aplikasi kecerdasan buatan, oleh karena itu dibuatlah sebuah sistem pakar untuk mendiagnosis penyakit hipertensi dengan metode Naive Bayes. 


\section{A. Perumusan Masalah}

Berdasarkan latar belakang permasalahan di atas yang dikaji dalam penelitian ini dapat dirumuskan:

1. Bagaimana membuat sistem pakar untuk mendiagnosis awal penyakit hipertensi beserta solusinya?

2. Memberikan informasi berupa penyakit yang menyerang serta penanganannya berdasarkan penalaran para pakar dengan menggunakan aplikasi sistem pakar?

\section{B. Pembatasan Masalah}

Pembatasan masalah dari perumusan masalah diatas adalah:

1. Sistem pakar diagnosis penyakit hipertensi metode yang digunakan dalam penelitian ini adalah metode Naive Bayes

2. Sistem pakar diagnosis penyakit hipertensi penelitian ini dilakukan dipoli umum

3. Sistem pakar diagnosis penyakit hipertensi menghasilkan output berupa no antrian yang dapat memudahkan pasien dalam melakukan pendftran

4. Sistem pakar penyakit hipertensi menghasilkan output berupa hasil diagnosis

5. Dalam pengembangan sistemnya menggunakan PHP dan Database My $S Q L$.

\section{Tujuan Penelitian}

Tujuan dari penelitian sistem pakar diagnosis penyakit hipertensi adalah merancang sebuah website yang dapat dijadikan media informasi bagi pasien untuk mendiagnosis penyakit hipertensi sehingga dapat membantu dalam pencegahannya.

\section{METODOLOGI PENELITIAN}

\section{A. Tempat dan Waktu}

1) Tempat Penelitian

RSUD pandeglang, Jl. Raya Labuan KM. 19, Kp. Pasir Angin Ds. Kadudampit Kec. Saketi , Kab. Pandeglang, Banten 42273.

2) Waktu Penelitian

Waktu penelitian dilakukan pada Dinas RSUD Pandeglangkurang lebih selama 1 bulan terhitung dari tanggal 8 Maret 2019 sampai dengan 8 april 2019.

\section{B. Tahapan Penelitian}

1) Teknik Pengumpulan Data

Istilah asing teknik pengumpulan data adalah adalah proses formal menggunakan teknik seperti wawancara dan daftar pertanyaan untuk mengumpulkan fakta tentang sistem, kebutuhan dan pilihan. (Indrajani, 2018).

\section{a. Observasi}

Observasi adalah mengamati. Observasi dilakukan dengan menggunakan indra penglihatan dan indra pendukung lainnya, seperti pendengaran, penciuman dan lainlain untuk mencermati secara langsung fenomena atau objek yang sedang kita teliti.

b. Wawancara

Wawancara adalah metode pengambilan data yang dilakukan dengan cara menanyakan kepada responden secara langsung dan bertatap muka tentang beberapa hal yang diperlukan dari suatu fokus penelitian. (A. Ghani dkk, 2016).

c. Studi Kepustakaan

Studi Kepustakaan dilakukan dengan cara mengumpulkan, membaca, dan mempelajari data-data dari berbagai media, seperti buku-buku, hasil karya tulis, jurnaljurnal penelitian, atau artikel-artikel dari 
internet yang berhubungan dengan masalah yang dibahas. (Indrajani, 2018).

2) Tahapan Perencanaan Sistem

Tahap desain sistem dapat dikerjakan setelah analisis maka dilakukan tahap perencanaan dan analisis sistem merupakan tahap kritis dan sangat vital. Setelah menganalisis maka perencaana sistem dapat dilakukan dengan guna mendapatkan gambaran seperti apa yang harus dibuat dan dituangkan kedalam sistem. Kemudian tahap desain dikerjakan guna memberikan pandangn yang jelas kepada pengguna mengenai sistem yang baru tersebut.Tahap seleksi sistem dibutuhkan pemahaman yang matang untuk menyeleksi teknik-teknik apa yang cocok dalam pelaksanaan maupun persiapan kebutuhan-kebutuhan dalam peracangan yang telah dilakukan .(Rosa A.S, 2017).

Salah satu model pengembangan perangkat lunak yang peneliti gunakan guna memecahkan kndala yang ditemui seiring dengn perkembngn skala sistem perangkat yang semakin besar yaitu SLDC ( software depelopment life cycle).

Perancangan dalam sistem pakar ini peneliti menggunkan SLDC model Waterfall yaitu model air terjun seiring juga dsebut model sekuensial linear ( sequential linear) atau alur hidup klasik (classic life cycle). Model ini menyediakan pendekatan alur hidup perangkat lunak secara terurut dimulai dari analisis, desain dan pengkodean.

\section{HASIL DAN PEMBAHASAN}

Objek Penelitian dalam pembuatan penelitian ini adalah pada RSUD Pandeglangyang beralamat di J1.Raya Labuan KM.19, Kp. Pasir Angin Ds. Kadudampit Kec. Saketi Kab. Pandeglang, Banten Kode pos. 42273. Dimana dalam penelitian ini peneliti melakukan studi kasus yang membahas masalah-masalah dalam mendiagnosis Penyakit Hipertensi dan Upaya Pencegahanya. Sebelum menganalisis suatu masalah ada baiknya mengetahui terlebih dahulu tentang sejarah, visi, misi dan struktur organisasi di lingkungan RSUD Pandeglangyang akan dijelaskan di bawah ini.

\section{A. Gambaran Umum Sistem yang Diusulkan}

Sistem pakar diagnosis penyakit hipertensi mengguakan metode Naive Bayes berbasis web ini diharapkan dapat mempermudah para petugas dalam mendiagnosis penyakit hipertensi.

Berikut dijabarkan flow of System yang Diusulkan.

1. Pasien memilih gejala dan mendaftarkan diri

2. Admin memproses data pasien.

3. Admin menginput dan memproses data seperti tabel penyakit, tabel gejala, tabel user, tabel rule dan tabel dataset.

4. Admin memberikan hasil diagnosis kepada pasien.

5. Kemudian hasil diagnosis di kembalikan ke pasien

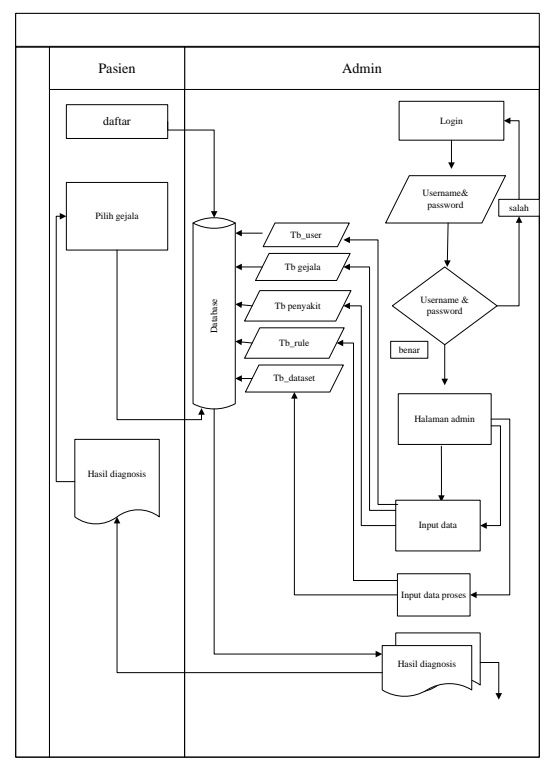

Gambar 1. Flow Of system Yang Diusulkan 
B. Diagram kontek yang di usulkan

Berikut adalah diagram kontek yang diusulkan untuk Sistem Pakar Diagnosis Penyakit Hipertensi di RSUD pandeglangsebagai berikut.

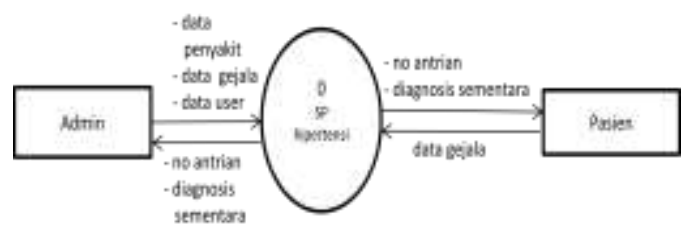

Gambar 2. Diagram kontek yang Diusulkan

\section{Data Flow Diagram (DfD) yang Diusulkan}

Data flow diagram yang diusulkan dari Sistem Pakar Diagnosis Penyakit Hipertensi di RSUD pandeglangdapat dilihat pada gambar dibawah ini

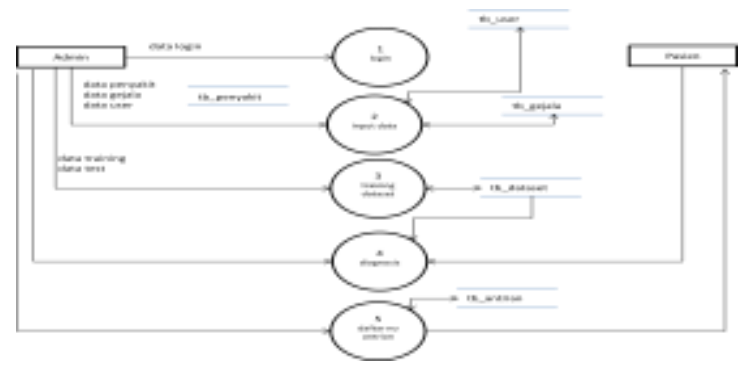

Gambar 3. DFD

D. Entity Relationship Diagram (ERD)

Entity Relationship Diagram (ERD) dari perancangan sistem pakar diagnosis penyakit Hipertendi di RSUD pandeglang



Gambar 4. ERD

E. Analisa Perhitungan Probabilitas Naive bayes Tabel 1. Probabilitas penyakit

\begin{tabular}{|l|l|l|}
\hline Penyakit & Jumlah & Probabilitas penyakit \\
\hline Hipertensi gestasional & 26 & 0.32098765432099 \\
\hline Hipertensi precklampsia & 47 & 0.58024691358025 \\
\hline Hipertenai eklamsia & 8 & 0.098765432098765 \\
\hline
\end{tabular}

Menghitung probabilitas penyakit

$\mathrm{P}($ Penggunaan penyakit $)=$ Hipertensi Gestasional

$\mathrm{P}($ Penggunaan penyakit $)=$ Hipertensi Preeklampsia

$\mathrm{P}($ Penggunaan penyakit $)=$ Hipertensi Eklamsia

$\mathrm{P}($ Penggunaan penyakit $=$ hipertensi gestasional $)$

$=$ jumlah penyakit hipertensi gestasional / jumlah penyakit

$=$ hipertensi gestasional + jumlah penyakit preeklampsia + jumlah penyakit eklamsia.

$=26 / 81=0,32$

\section{Probabilitas Gejala}

1) $\mathrm{P}$ ( gejala $=$ darah tinggi sebelum hamil | penyakit = hipertensi gestasional $)=1+($ jumlah gejala $=$ darah tinggi sebelum hamil dan penyakit = hipertensi gestasional ) / (jumlah penyakit =hipertensi gestasional +2$)=(1+7) /(26=2)=$ 0,29

2) $\mathrm{P}$ ( gejala = darah tinggi sebelum hamil $\mid=$ hipertensi praeklampsia $)=$ $1+($ jumlah gejala $=$ darah tinggi sebelum hamil dan penyakit preeklampsia $) /($ jumlah penyakit = hipertensi preeklampsia +2 ) $=(1+3) /(47+2)=0,08$. 
3) $\mathrm{P}$ ( gejala = darah tinggi sebelum hamil $\mid=$ hipertensi eklamsia $)=1+$ ( jumlah gejala $=$ darah tinggi sebelum hamil dan penyakit eklampsia )/ (jumlah penyakit = hipertensi elampsia +2$)$ $=(1+1) /(8+2)=0,2$

2. Diagnosis

a. $\mathrm{P}($ Gejala $=$ darah tinggi sebelum hamil $\mid x)=(P($ Jumlah gejala $=$ darah tinggi sebelum hamil $\mid$ penyakit = hipertensi gestasional $)$ x $\mathrm{P}($ Gejala $=$ darah tinggi pada kehamilan sebelumnya $\mid$ penyakit = hipertensi gestasioanal )) $\mathrm{x}$ P ( Penyakit = hipertensi gestasional $)=0,29 \times 0,32$ $\mathrm{x} 0,32=0,029$

b. $\mathrm{P}($ Gejala $=$ darah tinggi sebelum hamil $\mid x)=(P($ Jumlah gejala $=$ darah tinggi sebelum hamil $\mid$ penyakit = hipertensi gestasional $)$ x P ( Gejala $=$ darah tinggi pada kehamilan sebelumnya $\mid$ penyakit $=$ hipertensi praeklampsia )) $\times \mathrm{P}($ Penyakit $=$ hipertensi preeklampsia $)=0,8 \times 0,06$ $\mathrm{x} 0,57=0,0028$

c. $\mathrm{P}($ Gejala $=$ darah tinggi sebelum hamil $\mid x)=(P($ Jumlah gejala $=$ darah tinggi sebelum hamil $\mid$ penyakit = hipertensi gestasional $) \times \mathrm{P}($ Gejala $=$ darah tinggi pada kehamilan sebelumnya | penyakit $=$ hipertensi eklampsia)) x P $($ Penyakit $=$ hipertensi eklamsia $)=0,02 \times 0,3 \times 0,098=$ 0,059

3. Presentase Diagnosis

Rumus : Nilai Probabilitas / Total Probabilitas

1) Nilai presentase hipertensi gestasional

Nilai probabilitas $=(0,029 / 0,0385) \mathrm{x}$ 100

$$
\begin{aligned}
& =0,774 \times 100 \\
& =77 \%
\end{aligned}
$$

2) Nilai probabilitas $=(0,0028 / 0,0385) \mathrm{x}$ 100

$$
\begin{aligned}
& =0,072 \times 100 \\
& =7,2 \%
\end{aligned}
$$

3) Nilai probabilitas $=(0,0059 / 0,0385) \mathrm{x}$ 100

$$
\begin{aligned}
& =0,1532 \times 100 \\
& =15,32 \%
\end{aligned}
$$

\section{F. Implementasi Sistem}

Berikut ini dijelaskan implementasi aplikasi dari rancangan yang telah dibuat.

\section{Halaman utama untuk pasien}

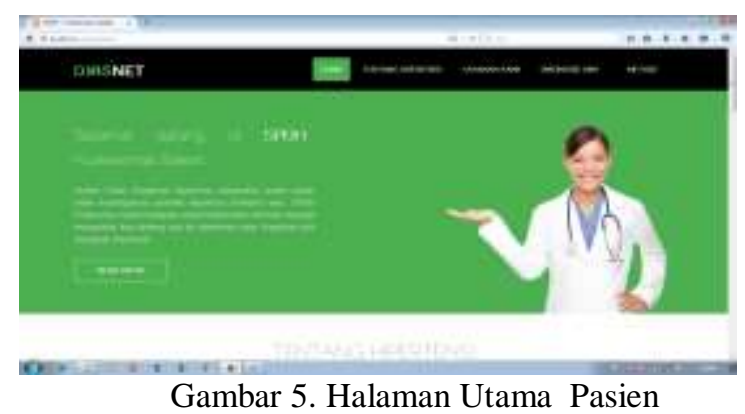

2. Form Pelayanan

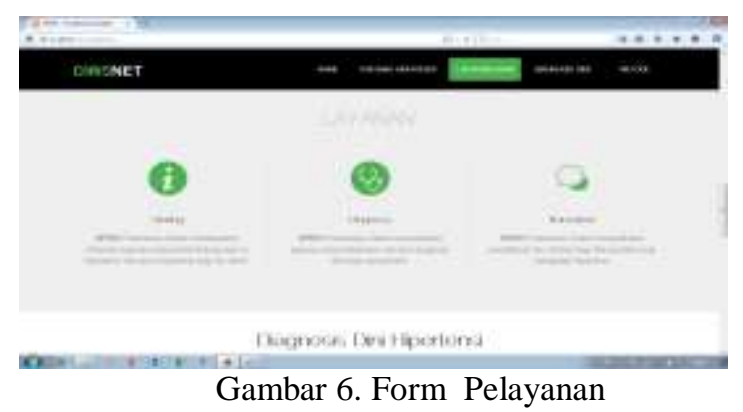

3. Diagnosis Dini Penyakit Hipertensi 


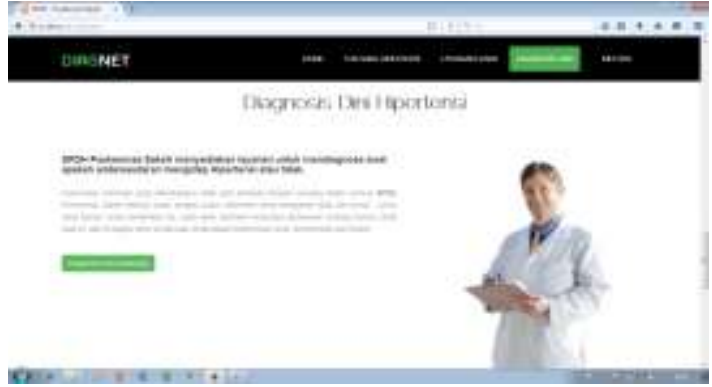

Gambar 7. Diagnosis Dini

\section{Halaman Login}

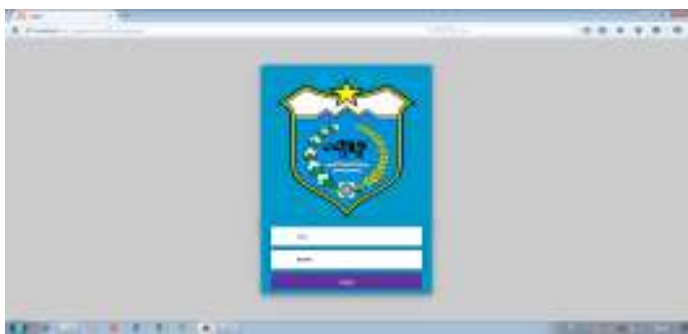

Gambar 8. Halaman Login

\section{Halaman admin}

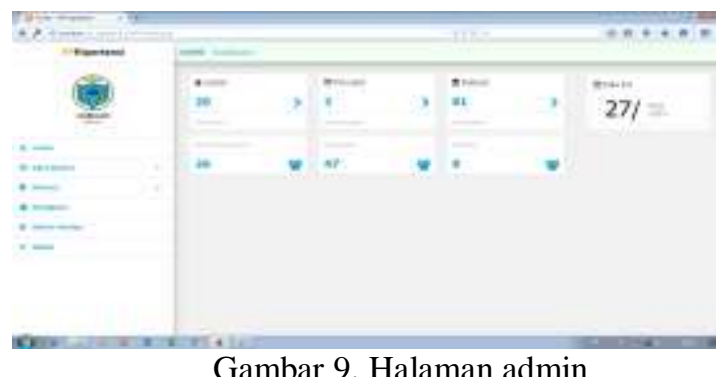

\section{Probabilitas Gejala}

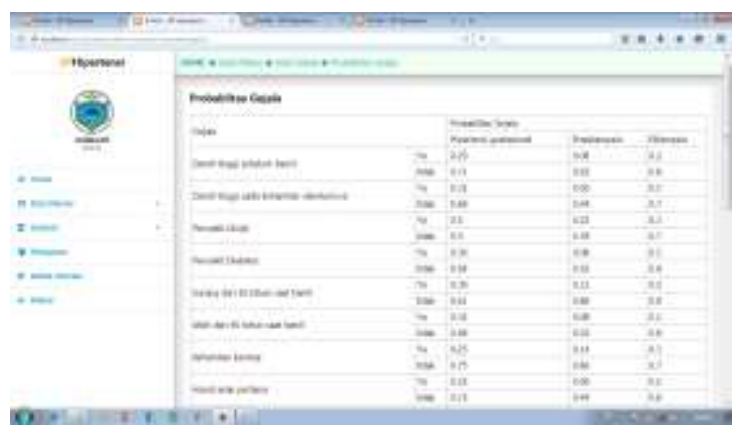

Gambar 10. Probabilitas Gejala
7. Data gejala

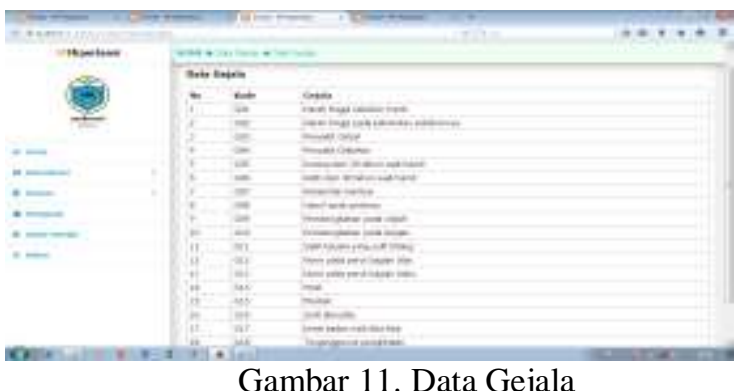

8. Probabilitas penyakit

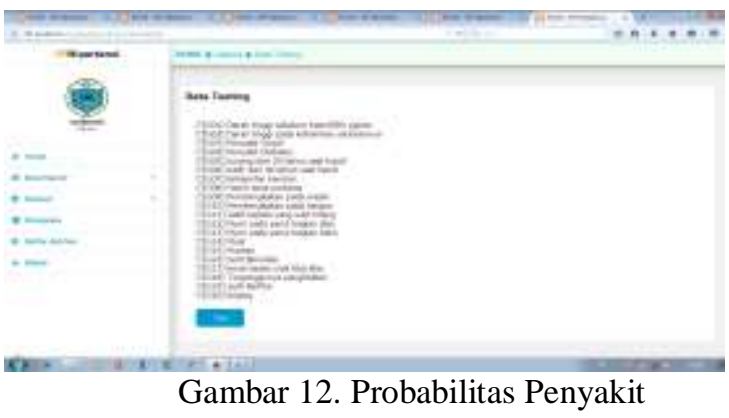

9. Data penyakit

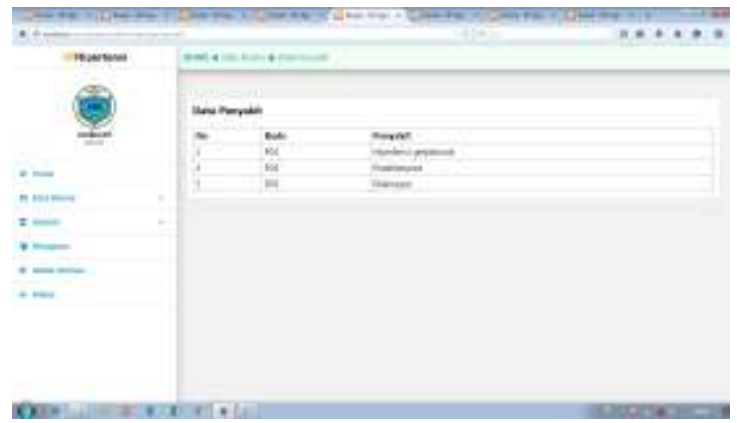

Gambar 13. Data penyakit

\section{Data testing}

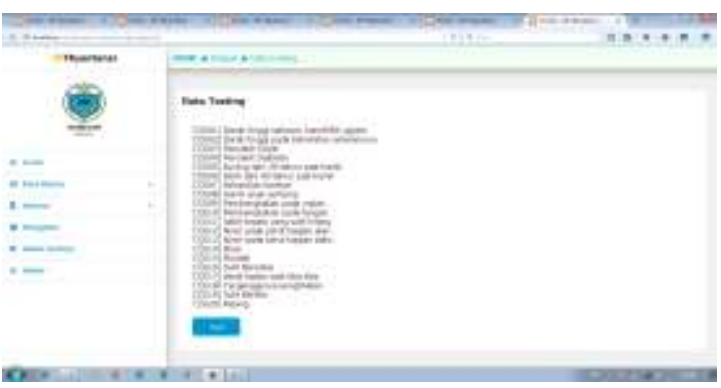

Gambar 14. Data Testing 


\section{Daftar Antrian}

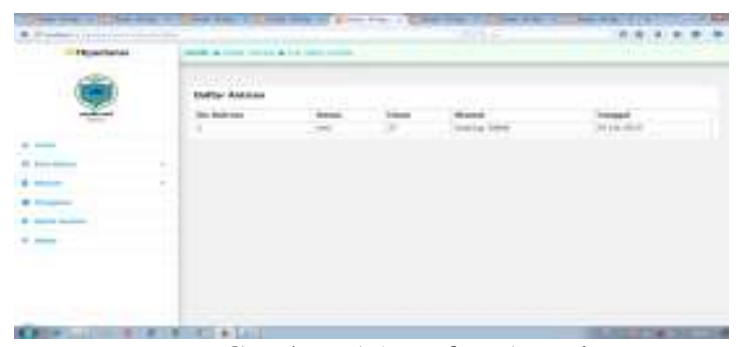

Gambar 15. Daftar Aantrian

\section{KESIMPULAN}

Berdasarkan hasil pembahasan teori pada penyakit hipertensi dapat disimpulkan sebagai berikut :

1. Aplikasi Sistem Pakar diagnosis penyakit hipertensi ini dapat membantu dokter dalam memberikan pelayanan kepada pasien.

2. Aplikasi ini memberikan solusi kepada pasien untuk mendapatkan informasi terkait penyakit hipertensi yang dideritanya tanpa harus mengantri.

\section{REFERENSI}

[1] Abd. Rahman A. Ghani. (2016). Metodelogi Penelitian Tindakan Sekolah.Jakarta: Rajawali Pers.

[2] B.Herawan Haryadi.—Ed.1,Cet,1- Sistem pakar. Yogyakarta: Depublish, Januari 2016.

[3] Canggih Ajika Pamungkas. (2017). Pengantar dan Implementasi Basis Data. Yogyakarta: Deepublish.

[4] Indrajani.(2018).Database design All in one-Theory,and case study.Jakarta:Kompas Gramedia.

[5] Indrajani.(2015).Database Design Case Study All in one.Jakarta:Kompas Gramedia.

[6] Indrajani.(2011).Perancangan Basisdata dalam All in 1.Jakarta:Gramedia.

[7] Muhamad Ridwan,S.Pd, M.Pd 2017. Mengenal, Mencegah, Mengatasi Silent Killer, "Hipertensi". Penerbit Romawi Press.

[8] Maniah. \& Dini Hamidin. (2017). Analisis dan Perancangan Sistem Informasi Pembahasan Secara Praktis Dengan Contoh Kasus, Yogayakarta : Deepublish.

[9] Nita Merlina \& Rahmat Hidayat. (2012). Perancangan Sistem Pakar. Penerbit: Ghalia Indonesia.
[10] Perancangan Basis Data dalam All in 1/oleh Indrajani.-Cet. 1.-Jakarta: Kompas Gramedia, Maret 2011.

[11] Roni Abdulloh. (2018). 7 in 1 Pemrograman Web untuk Pemula. Jakarta: Kompas Gramedia

[12] Rosa A.S,M.S.(2017). Rekayasa Perangkat Lunak Terstruktur dan Berorientasi Objek. Bandung: Informatika.

[13] Widodo, Agus Wahyu \& Diva Kurnianingtyas. (2017) Sistem Basis Data, Malang : UB Press

[14] Yan Watequlis Syifudin, dkk. (2018). Dasar Pemrograman, Malang: Polimena Press.

[15] Anonim. (2017).Teorema bayes diambil 10 maret 2019 dari httpz://www.google.com/amp/s/informatikalogi.com/algorit ma-naive-bayes/amp/

[16] Dewi Sulistyaningsih. (2017). Pengertian Diagnosa Beserta Tahapan Melakukan Diagnosa. Diambil 18 Maret 2019, dari http://rocketmanajemen.com/definisi-diagnosa/

[17] Fridayanthie, EW. (2016). Rancang Bangun Sistem Informasi Permintaan ATK Berbasis Internet. Diakses 04 April 2019 dari. http://ejournal.bsi.ac.id/ejurnal/index.php/khatulistiwa/articl e/download/1

[18] Omar pahlevi, Astriana mulyani \& Miftahul Khoir.(2018).Sistem Invetori Barang Menggunakan Metode Object Oriented diakses 8 april 2019, dari http://ejurnal.Ippmunsera.org/index.php/Prosisko/article/download/ $587 / 612$

[19] Padeli (2014) Cara mudah membangun informasi dengan website,Serang:

[20] Pengajarku. (2018). Analisis Sistem, Pengertian, Tujuan, Fungsi dan Contohnya. Diambil 03 April 2019, dari https://pengajar.co.id/analisis-sistempengertian-tujuan-fungsi-tahapan-dan-contohnya/

[21] Retno Tri Wulandari. (2016).Klasifikasi Naive Bayes diambil $\quad 10 \quad$ April 2019,dari publikasi.dinus.ac.id/index.php/jais/article/viewfile/1 032772 